\title{
Noise Attenuation on F-k Domain Using Radial Transform and the SVD Method
}

\author{
Rafael R. Manenti*, Lucas J. A. de Almeida and Milton J. Porsani, CPGG/UFBA and INCT-GP/CNPq/Brazil
}

Copyright 2014, SBGf - Sociedade Brasileira de Geofísica.

Este texto foi preparado para a apresentação no VI Simposio Brasileiro de Geofísica, Porto Alegre, 14 a 16 de outubro de 2014. Seu conteudo foi revisado pelo Comitê Técnico do VI SimBGf, mas não necessariamente representa a opinião da SBGf ou de seus associados. E proibida a reprodução total ou parcial deste material para propositos comerciais sem prévia autorização da SBGf.

\begin{abstract}
In this paper, a novel method for linear noise attenuation on shot-gathers is presented. The procedure combines the 2-D Fourier transform, the radial transform and the singular value decomposition (SVD). The method is carried as follows: (i) the 2D Fourier transform is applied, generating the $f-k$ spectrum; (ii) the radial transform of the portion of the $f-k$ spectrum coincident with the linear events is performed, centered in the $(0,0)$ frequency; (iii) the SVD method is applied inside the aforementioned portion using sliding windows and maintaining all but the first eigenimage.
\end{abstract}

\section{Introduction}

The ground roll is a dispersive linear noise that hides the reflections of the seismogram, caused by the Rayleigh wave, with low frequency, low velocity and high amplitude. This noise needs to be filtered because its presence lowers the signal/noise ratio, making the velocity analysis more difficult and impairing the quality of the stacked section.

The filtering of linear events using the 2D Fourier Transform, known as the $\mathrm{f}-\mathrm{k}$ Method, has been widely used in seismic data. The method consists of performing the 2-D Fourier Transform of the data, and locating the structures related to the linear events in the $f-k$ spectrum. This structures are then bounded by a polygon, and every coefficient inside this area is zeroed out. While this method is very effective for removing linear events, problems such as aliasing and artifacts are often noticed.

The Radial Transform method was introduced by Ottolini, 1979, and Claerbout, 1983, for seismic migration, separating up-going and down-going waves and for imaging algorithms. Henley, 1999, used the radial transform for seismic processing, transforming the data, from the distance-time domain (XT) to the velocity-time or angle-time domain (RT), making linear events show up as vertical events with low frequency and conserving the structure and frequency of the sub-horizontal events. Because of this change in the frequency of the data, Henley, 2000, used the low cut filtering in the RT domain for coherent noise attenuation.

The SVD filtering (Singular Value Decomposition) is used for enhancing the spatial coherence of reflections and also for filtering many kinds of noise (Freire, 1986, Bekara and Van Der Baan, 2007, Porsani et al., 2013). The method proposed by Porsani (2010) works with a moving window that runs through the whole data, after the normal moveout correction. The NMO correction turns the reflections horizontal, and the SVD extracts the central trace of the band, reconstituting the trace with the first $\mathrm{K}$ eigenvalues.

The SVD technique has already been used with efficiency in a window-based approach in the $f-k$ domain. In this paper, an alternative method for $\mathrm{f}-\mathrm{k}$ filtering is provided. After the 2-D Fourier Transform, the polygon is chosen by means of the Radial Transform, where it is defined by an angle aperture that contains the linear event structures to be filtered. Instead of zeroing the coefficients, the SVD is applied in angular sectors within this angle aperture, effectively preserving the reflections while attenuating the linear events.

\section{The Radial Transform}

The Radial Transform (RT) is an amplitude rearrangement of the seismic data $S(x, t)$, usually placed in the distancetime domain (XT), to the angle-time or velocity-time domain (RT) (Henley, 1999).

\section{The SVD Filtering}

The SVD method consists in decompose a matrix $A$ into three different matrices. Two orthonormal matrices, $U$ and $\mathrm{V}$, will have the eigenvectors of the matrix $A$, and one matrix $\Sigma$, with the singular values in the main diagonal. This decomposition can be shown in (1):

$$
\mathrm{A}=\mathrm{U} \Sigma \mathrm{V}^{T} .
$$

The singular values of $A$ in $\Sigma$ are arranged in a decreasing order of magnitude, which means that $\left|\sigma_{1}\right| \geq\left|\sigma_{2}\right| \geq \ldots \geq$ $\left|\sigma_{n}\right|$.

Porsani et al. (2009) proposed a method where for each trace in the seismogram that we want to filter, a group of neighbor traces can be collected, forming a moving window. This window can be decomposed with the SVD method and after that, a restitution of the central trace is made, using the first $\mathrm{K}$ eigenimages, as in (2):

$$
\tilde{d}\left(t, x_{j}\right)=\sum_{k=1}^{K} \sigma_{k} u_{k}(t) v_{k}\left(x_{j}\right) .
$$

\section{Methodology}

As the main goal of this paper was to filter the ground roll, the SVD filtering was applied in the RT domain. As the SVD works as a moving window through the data in the XT domain, in the RT domain it works as a moving sector with same origin. The method was applied in the Line 5090 of the Tacutu Basin. The data contains 179 shots with 96 channels, 1001 samples with sampling interval of $4 \mathrm{~ms}$ in a symmetric split-spread geometry with offsets from -2500 $\mathrm{m}$ to $-150 \mathrm{~m}$ and from $150 \mathrm{~m}$ to $2500 \mathrm{~m}$, with $50 \mathrm{~m}$ interval between geophones. The distance interval of the shots is $200 \mathrm{~m}$, and a CMP coverage of 12 fold. 
The data was pre-processed (geometry, editing and mute), then the Direct 2-D Fourier Transform was applied. The Direct RT was applied on the f-k spectrum, selecting an angular sector based on an angle aperture of. The SVD method, with the first eigenimage conserved only. After the filtering, the inverse radial transform and the inverse 2D Fourier Transform were applied, returning the data to the distance-time domain. The result of the inverse radial transform was sorted into CMP families, then, the velocity analysis was made. After this procedure, the NMO correction was applied, followed by the stacking process.

\section{Results}

In the original data in Figure $3 a$, the direct radial transform was applied after the 2-D Fourier Transform, followed by the SVD filtering. The result of this filtering and the usual $f-k$ method can be seen in Figure $3 b$ and Figure $3 c$, respectively. The average amplitude spectrum of this process is shown in Figure 1, where the filtering has lowered the amplitude of the low frequency of the data. In Figure 5, the semblance of the aforementioned shotgathers are shown, indicating a clear improvement in the representation, which aids velocity picking and analysis.

\section{Conclusions}

The use of the SVD and the radial transform in the $f-k$ domain showed up to be a good alternative for attenuation of the groud-roll compared to the usual $f-k$ method, since the radial transform enables to focus the filtering in a angular sector, which contains the noise to be attenuated. As opposed to zeroing the coefficients in the angular sector, the SVD attenuates only the coherent noise, preserving any signal that may be located in the sector.

\section{References}

Claerbout, J. F., 1983, Ground-Roll and Radial Traces., Stanford Exploration Project Report, SEP-35, pp. 43-53.

Freire, S. L. M., 1986 Aplicações do método de decomposição em valores singulares no processamento de dados sísmicos., Tese de Doutorado, Universidade Federal da Bahia, Salvador, Brasil.

Henley, D. C., 1999, The radial trace transform: an effective domain for coherent noise attenuation and wavefield separation., In: Expanded Abstract, 69th Annual SEG Meeting., pp. 1204-1207, SEG.

Henley, D. C., 2000, More radial trace domain applications., Crewes Research Report Volume 12, pp. 1-14.

Ottolini, R., 1979, Migration of Radial Trace Sections., Standford Exploration Project Report, SEP-20, pp. 97-115.

Porsani, M. J.; Silva, M. G.; Melo, P.E. M. and Ursin, B., 2009, Ground-roll attenuation based on SVD filtering., In: Expanded Abstract, 79th Annual SEG Meeting., pp. 33813385, SEG.

Porsani, M. J., 2010, An adaptive local-slope svd filtering approach to enhance events on seismic section: SEG Expanded Abstracts, 29, 37173722.

\section{Acknowledgements}

The authors wish to express their gratitude to CAPES, INCT-GP/CNPq/MCT, PETROBRAS, ANP,
FINEP, FAPESB Brazil for financial support. We also thank LANDMARK for the licenses granted to CPGG/IGEO/UFBA.

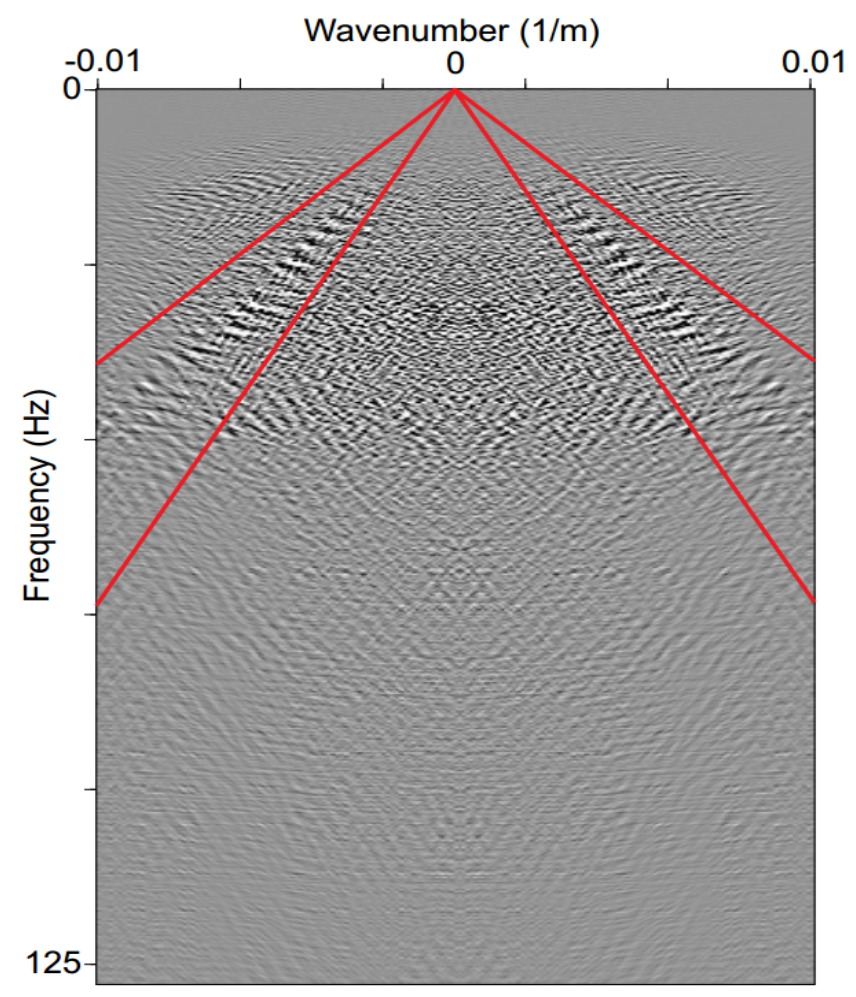

Figure 1: F-k spectrum of figure 3a. The red lines represent the angle sector used in the radial transform.

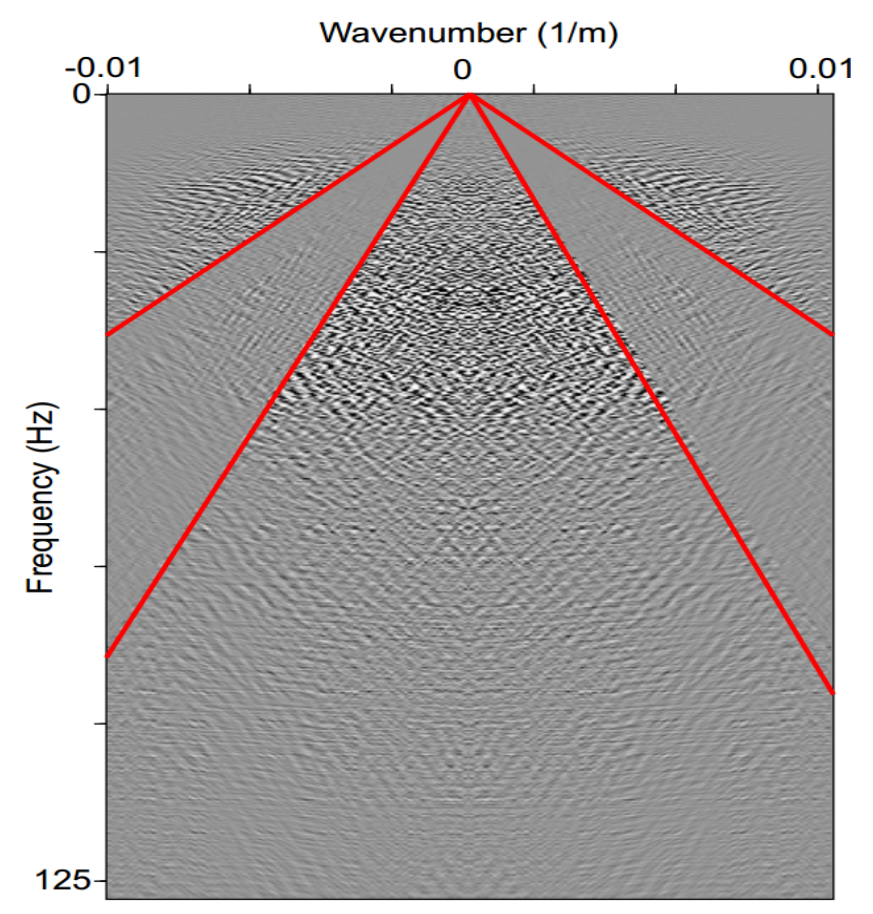

Figure 2: F-k spectrum of figure 3b. The red lines represent the angle sector used in the radial transform. 


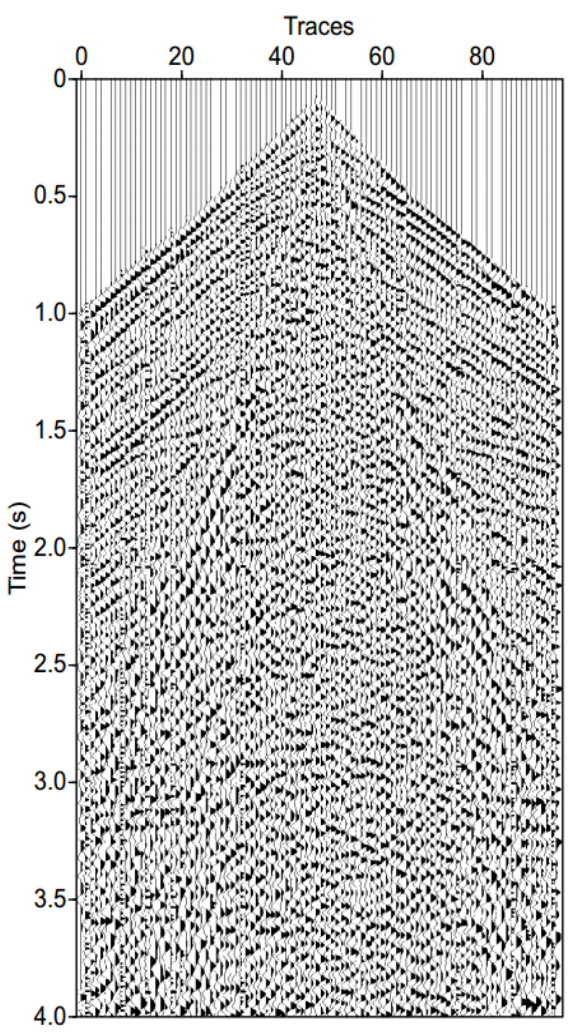

(a)

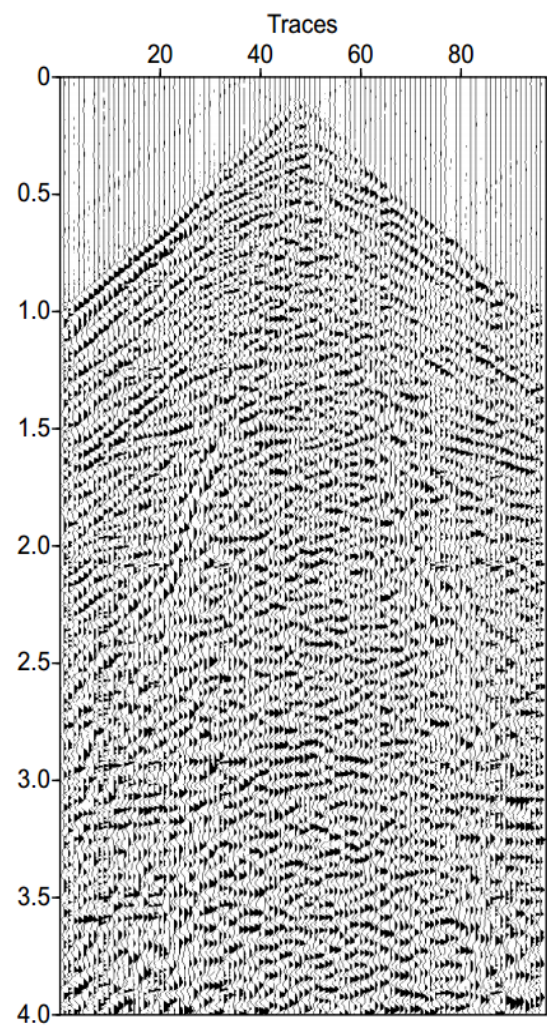

(b)

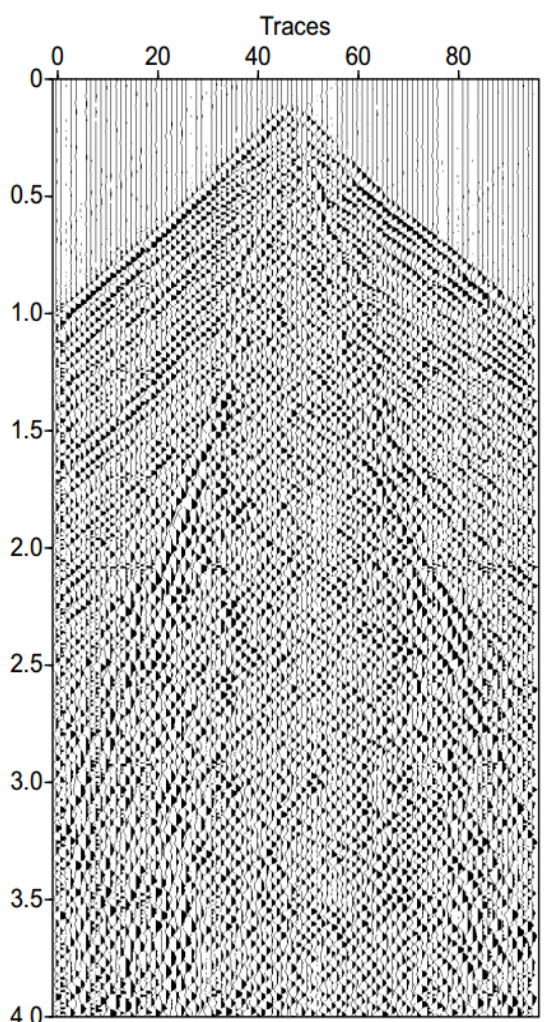

(c)

Figure 3: Original shot-gather in (a), filtered shot-gather in (b), residue in (c).

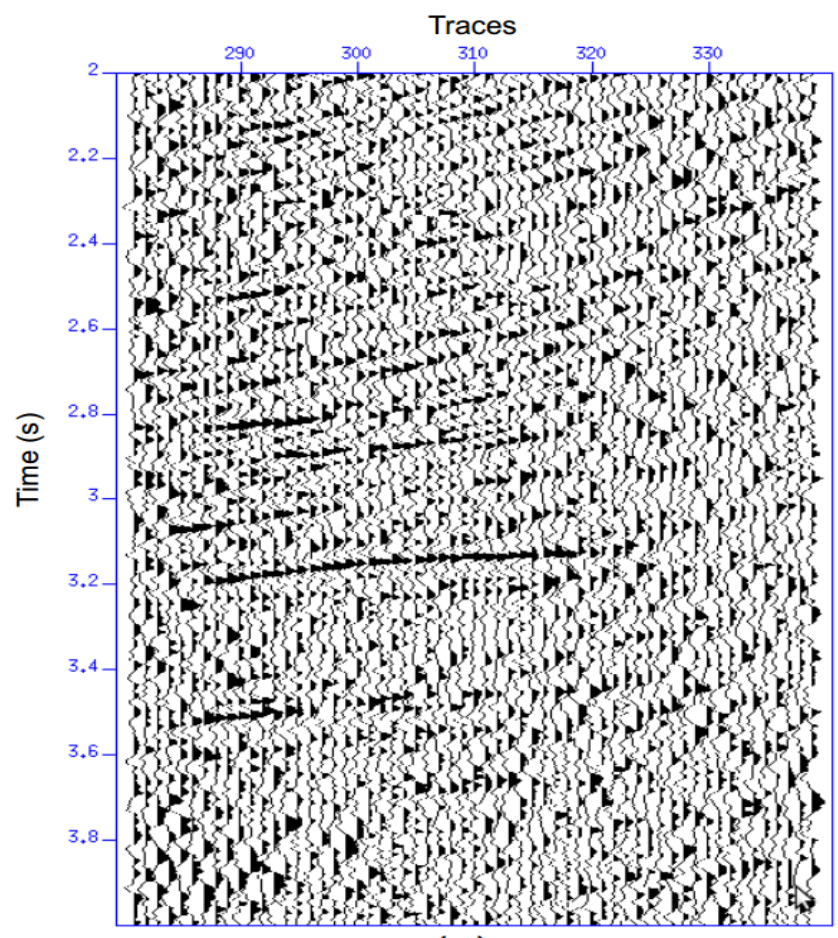

(a)

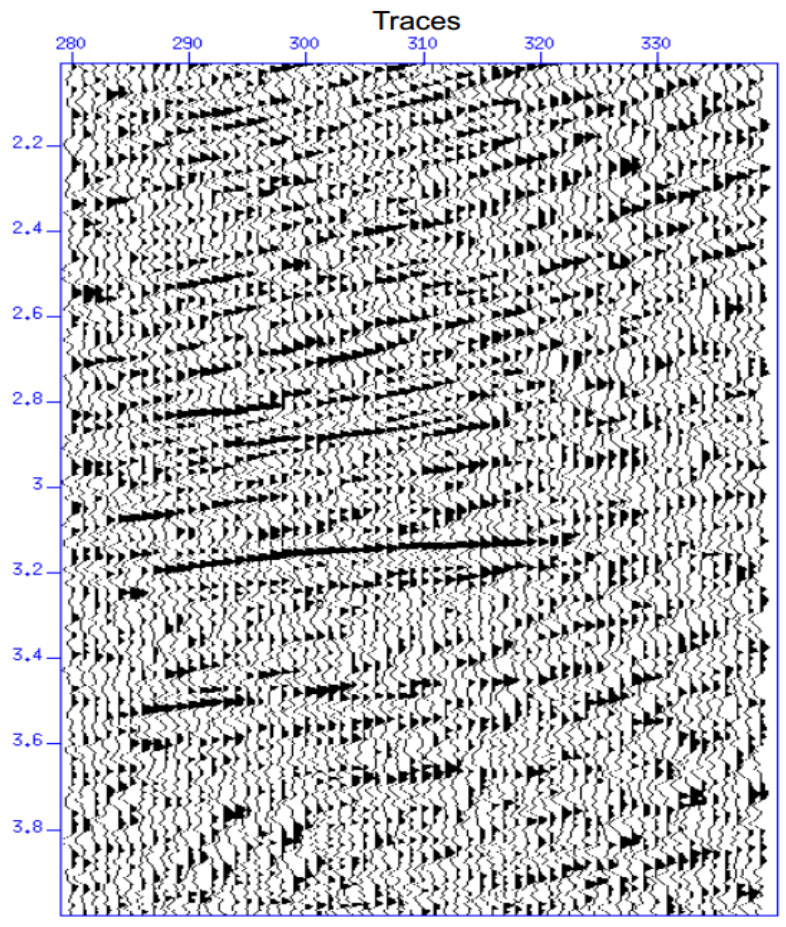

(b)

Figure 4: Detail of the stacked section: original in (a) and filtered in (b). 


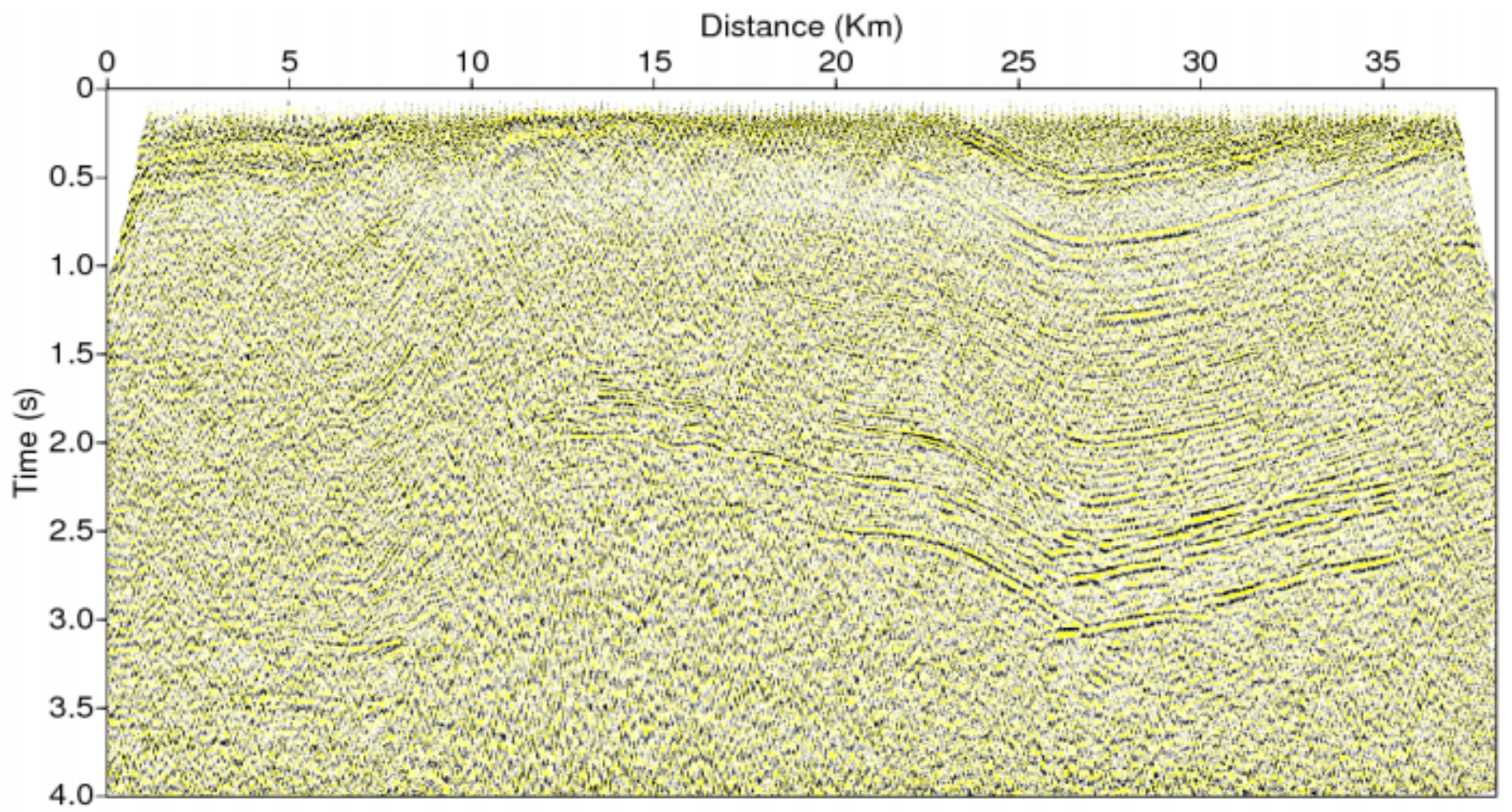

(a)

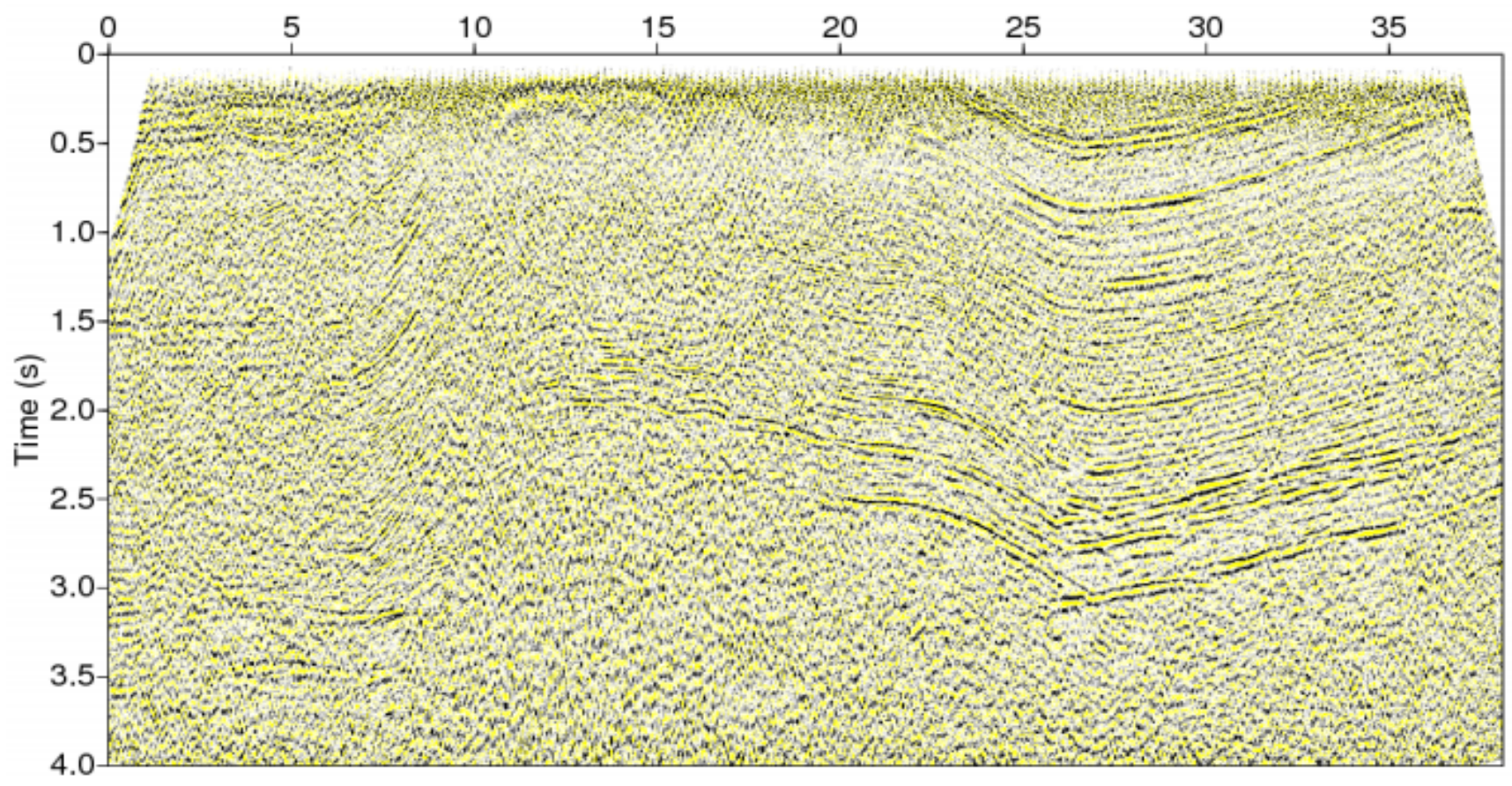

(b)

Figure 5: Stacked section: original in (a), and filtered in (b). 